\title{
Sustainable engineering master module - insights from three cohorts of European engineering team
}

\section{Bartlomiej Gladysz}

Faculty of Production Engineering, Warsaw University of Technology, ul. Narbutta 85, 02-524 Warsaw, Poland

Email: bartlomiej.gladysz@pw.edu.pl

\section{Marcello Urgo}

Mechanical Engineering Department,

Politecnico di Milano,

via La Masa 1, 20156 Milan, Italy

Email: marcello.urgo@polimi.it

\section{Tim Stock}

Chair for Sustainable Corporate Development, Technical University of Berlin, Pascalstr. 8-9, 10587 Berlin, Germany

Email: stock@zvei.org

\section{Cecilia Haskins}

Department of Mechanical and Industrial Engineering,

Norwegian University of Science and Technology,

S.P. Andersens vei 5, 7491 Trondheim, Norway

Email: cecilia.haskins@ntnu.no

\section{Felix Sieckmann*}

Fraunhofer Institute for Production Systems and Design Technology,

Pascalstr. 8-9, 10587 Berlin, Germany

Email: felix.sieckmann@ipk.fraunhofer.de

*Corresponding author

\section{Elzbieta Jarzebowska}

Faculty of Power and Aeronautical Engineering, Warsaw University of Technology, ul. Nowowiejska 24, 00-665 Warsaw, Poland

Email: elajarz@meil.pw.edu.pl 


\title{
Holger Kohl
}

Chair for Sustainable Corporate Development, Technical University of Berlin, Pascalstr. 8-9, 10587 Berlin, Germany

Email: holger.kohl@tu-berlin.de

\section{Jan Ola Strandhagen}

Department of Mechanical and Industrial Engineering, Norwegian University of Science and Technology, S.P. Andersens vei 5, 7491 Trondheim, Norway

Email: ola.strandhagen@ntnu.no

\section{Tulio Tollio}

Mechanical Engineering Department, Politecnico di Milano, via La Masa 1, 20156 Milan, Italy

Email: tullio.tolio@polimi.it

\begin{abstract}
Mobility and transnational migration are current social developments among the population of the European Union. These developments in both society-at-large and companies, linked to the challenges of sustainability, lead to new requirements for working in the European Union. Teaching and learning in higher education needs to adapt to these requirements. As a result, new and innovative teaching and learning practices in higher education should provide competencies for transnational teamwork in the curriculum of tomorrow's engineers in order to ensure their competitiveness in the job market. A transnational project-oriented teaching and learning framework, which provides the future key competencies for young engineers was implemented in the course European Engineering Team (EET). Engineering students from four countries participated in a new project-based course that focused on the development of innovative and sustainable products and opportunities. The goal of this paper is to present results and lessons learnt from three cohorts of EET.
\end{abstract}

Keywords: sustainability; innovation; engineering education; multinational; multidisciplinary; project-based learning.

Reference to this paper should be made as follows: Gladysz, B., Urgo, M., Stock, T., Haskins, C., Sieckmann, F., Jarzebowska, E., Kohl, H., Strandhagen, J.O. and Tollio, T. (2020) 'Sustainable engineering master module - insights from three cohorts of European engineering team', Int. J. Sustainable Manufacturing, Vol. 4, Nos. 2/3/4, pp.413-432.

Biographical notes: Bartlomiej Gladysz is Assistant Professor and Vice Director for Research of The Institute of Production Systems Organization of the Warsaw University of Technology. He received his $\mathrm{PhD}$ in Machine Building and Exploitation for the thesis on applications of RFID in manufacturing companies. 
Marcello Urgo is a Professor of Integrated Manufacturing Systems and Manufacturing Technologies at Politecnico di Milano. He has carried out research activities at the Research Laboratory on Engineering and Management Intelligence at the SZTAKI in Budapest and at the IPH - Institut fuer Integrierte Produktion Hannover. His main research fields cover project scheduling approaches for production planning under uncertainty, production process modelling for production planning in complex manufacturing systems, design approaches for manufacturing systems to cope with uncertainty to provide robust solution and proper reconfiguration paths.

Tim Stock studied Industrial Engineering at Otto-von-Guericke-University Magdeburg until 2012. In 2018, he received his Dr-Ing from Technical University of Berlin for his work on sustainable entrepreneurship. Subsequently, he joined the German Electrical and Electronic Manufacturers' Association. As a research fellow, he continues his research at the Chair for Sustainable Corporate Development in the areas of sustainable manufacturing and entrepreneurship.

Cecilia Haskins entered academia after more than 30 years in industry including entrepreneurial initiatives. Her educational background includes a BSc in Chemistry from Chestnut Hill College, and an MBA from Wharton, University of Pennsylvania. This combination has contributed to her ability to understand issues with an insider's view of both the business environments and the technical solution domains. She is recognised as a Certified Systems Engineering Professional since 2004. After earning her PhD in Systems Engineering from NTNU, she has focused her research interests on engineering education, sustainable development, and global production systems.

Felix Sieckmann received his MSc in Mechanical Engineering from Technical University of Berlin in 2015. He continued working there as a Research Engineer, before joining the Fraunhofer Institute for Production Systems and Design Technology in 2019 as the Head of the Department for Quality Management. His research focuses on learning factories and lean production systems.

Elzbieta Jarzebowska is a Professor at the Institute of Aeronautics and Applied Mechanics, Power and Aeronautical Engineering Department, Warsaw University of Technology, Warsaw, Poland. Her research and teaching include multibody system dynamics, control of UAV, ground, underwater and space vehicles, robotics, geometric control theory. She authored about 150 papers, chapters in monographs, student books and monographs. She worked for Automotive Research Centre and Engineering Research Centre for Reconfigurable Machining Systems at University of Michigan, Ann Arbor and for Ford Motor Company Research Laboratories, Dearborn, MI, USA. She also leads international Erasmus + based projects dedicated to modern teaching methodologies.

Holger Kohl studied Industrial Engineering at the Technical University of Berlin and the University of California and received his doctorate in 2007. Since 2013, he has headed the division Corporate Management at the Fraunhofer Institute for Production Systems and Design Technology. Additionally, he is a Professor for Sustainable Corporate Development at the Technical University of Berlin. His research interests include knowledge management, benchmarking, sustainable manufacturing and Industry 4.0. 
Jan Ola Strandhagen is Head of the Production Management Research Group, and Full Professor in Production and Quality Engineering at the Norwegian University of Science and Technology (NTNU). He is the Research Director of the Centre for Research-based Innovation (CRI) Norwegian Manufacturing (NORMAN), as well as Project Manager of a number of knowledge-building and innovation projects carried out in close collaboration with industry. $\mathrm{He}$ is currently heading the development of the Faculty of Engineering, Science and Technology strategic science plan for sustainable and innovative industry in Norway, working closely with industry to ensure high industrial relevance of education and research carried out at the faculty. His present fields of interest are manufacturing strategy, operations management and logistics, with particular focus on control models for real-time control of global value chains.

Tulio Tollio is a Full Professor of Manufacturing and Production Systems, Integrated Production Systems and Reconfigurable Manufacturing Systems at Politecnico di Milano. He is the Director of ITIA-CNR (Institute of Industrial Technologies and Automation of the National Research Council of Italy) and Associate Editor of the SME Journal of Manufacturing Systems, is a fellow of the International Academy for Production Engineering (CIRP), member of the High Level Group (HLG) of the EU platform Manufuture and member of the Industrial Research Advisory Group of EFFRA (European Factory of the Future Research Association). He has carried out research activities at the Laboratory for Manufacturing and Productivity (LMP) of the Massachusetts Institute of Technology (MIT).

This paper is a revised and expanded version of a paper entitled 'Sustainable engineering master module - insights from three cohorts of European Engineering Team' presented at the 16th Global Conference on Sustainable Manufacturing Lexington Kentucky, USA, 2-4 October 2018.

\section{Introduction}

Conventional teaching methods rarely prepare graduates to deal with problems that require them to apply their knowledge to new domains (Reich, 1990). Vernon (2000) concluded that an effective learning program in engineering education should be:

1 student-centred

2 project-oriented

3 include some elements of economics and management.

Jack (2011) identified key actions to improve the quality and effectiveness of engineering education in manufacturing, e.g., encourage students to pursue global travels and projects, incorporate topics and courses that support global manufacturing and, in particular, encourage teaching methods that actively engage students.

Sharma et al. (2017) evaluated approaches to teaching sustainability concepts in multidisciplinary classes of engineering students. They found that course organisation, student difficulties working in multidisciplinary teams, and limited student engagement in projects are barriers in such courses. Several authors presented case studies of teaching sustainable engineering in single-university environment by multidisciplinary approach and embodying sustainability in other engineering curriculum (Perdan et al., 2000), such 
as chemical (Glassey and Haile, 2012) and mining and petrochemical (Shields et al., 2014), or by presentation of sustainable manufacturing educational case studies (Sengupta et al., 2017). Stansinoupolos et al. (2013) presented an integrated approach to sustainable engineering based on the application of systems engineering. There are a number of initiatives relating to new forms of collaboration with industry (Paci et al., 2013), but very few multi-university initiatives. So-called learning factories are proposed to develop the competencies of engineers in Europe and promote transfer of technology from science to production (Ziemian and Sharma, 2008). However, that concept does not include the initial phases of new product development; i.e., the conceptual, research and analytical tasks necessary to be performed. Learning factories are worth noting as they apply principles of experiential learning. Experiential learning was introduced with the works of Dewey (2007), Kurt Lewin (Schein, 1996), Piaget (1964), Kolb (1984) and Kolb and Kolb (2005). Several projects have incorporated action-based and transnational curricula in engineering education. They fall into two categories; virtual and physical collaborations. For virtual-oriented see Kurtz et al. (2007), May et al. (2014), Paasivaara et al. (2013), Petrea and Velescu (2014) and POLE (2018). The physical-oriented approach is characterised by short-term, practice-oriented working phases where students convene at a specific location. It includes hands-on experiments and case studies for 16 learners established between Portuguese and German organisations (BASE, 2017). 28 weeks long, a transnational course was prepared by four European (France, Germany, Ireland, UK) universities in the area of construction engineering and management (Lane, 1994).

Most educational initiatives do not combine virtual and physical approaches. There are no guidelines available that combine experiential learning principles for teaching industrial engineers the problems of new product development with an emphasis on sustainability, systems engineering and new product development. Such initiatives should also focus on the elimination of barriers presented by Sharma et al. (2017). Therefore, the aim of this paper is to present some practices and lessons learnt from a virtual- and physical-oriented, multidisciplinary, transnational and sustainability-oriented initiative for the education of engineers, covering all phases of new product development process.

\section{Concept of the master course}

The master course of the European Engineering Team (EET) consists of specific course elements for training key competencies in engineering which have been derived from recommendations of bodies of the United Nations and European Union. The course follows the idea of project-based teaching. The project work of the students is divided in presence phases at the partner universities of one-week each and in phases for online collaboration. A so-called diamond model for the development of innovations in start-ups (Stock et al., 2017) provides the work structure and important work phases for the students. Additionally, the project work is supplemented by online lectures which provide the required know-how in the field of sustainable engineering (Figure 1). For finding and developing specific solutions during the project work, the students are running through a learning cycle (Figure 2) based on the ideas of Kolb (1984) and Kolb and Kolb (2005). This cycle aims at realising a high learning efficiency by applying specific steps. First, the students clarify the engineering task. By running through an iterative cycle of analysis and synthesis, the students develop solutions for the defined task. In order to validate the 
solutions, experiments and tests are conducted subsequently. Finally, the students draw conclusions and learn from the previous steps. Based on the lessons learned, they need to decide whether to exit the cycle with a feasible solution, to slightly adapt the task in form of a small iteration, or to perform a pivot and essentially change the task. Motivation, knowledge, and creativity are the main forces supporting the learning cycle. Thus, the supervisors are fostering these forces by proving an inspiring learning environment and creativity techniques, as well as necessary methods and tools during the cycle. The detailed teaching and learning framework of the EET is presented in Stock and Kohl (2018).

Figure 1 Sustainability orientation of EET

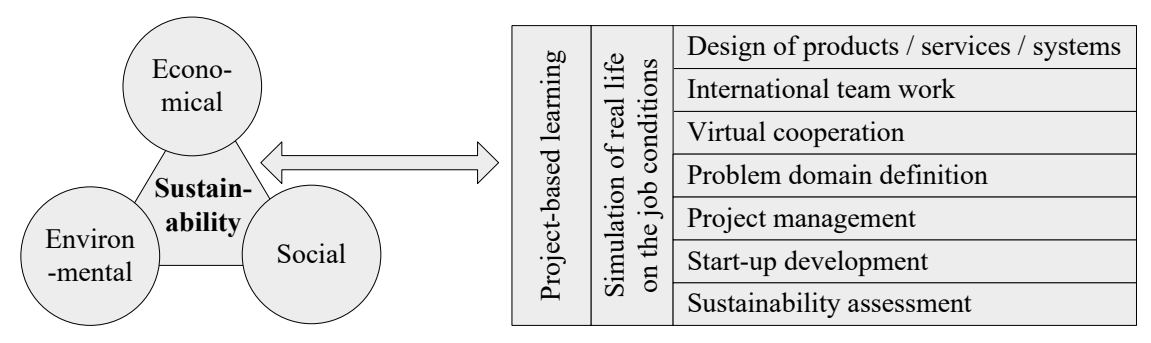

Figure 2 Learning cycle

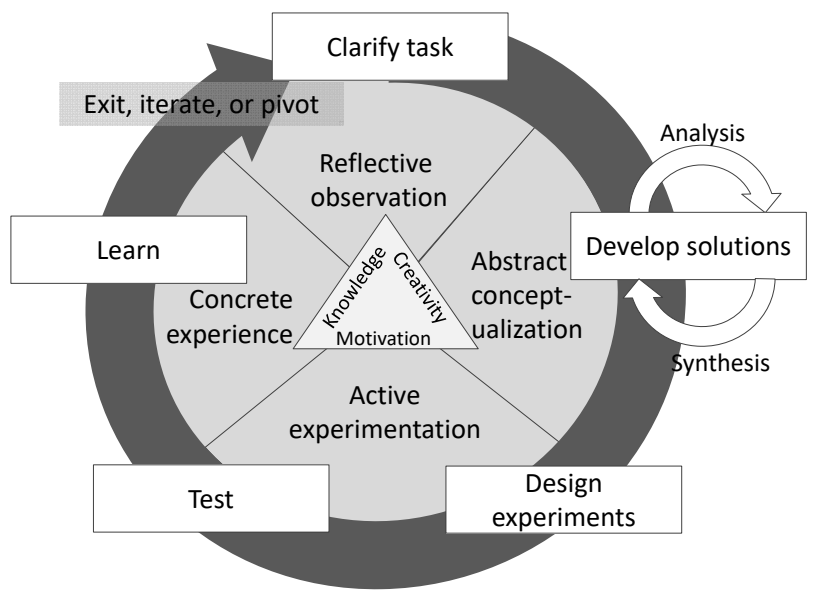

\section{Characteristics of cohorts}

Table 1 presents main characteristics of three cohorts conducted within the EET teaching program. The structure of the first and second cohort strictly followed the rules described in Section 2. The third cohort was not initially planned, but due to the success of preceding cohorts, partnering universities decided to conduct an extra cohort. One EET cohort was planned as a two semester long project with four meetings (one at each university). Due to lessons learnt from the first and second cohort, and administrative limitations, the third cohort was executed implementing some changes, i.e.: 
- A smaller group of students (eight instead of 13-16) worked in shorter period (one instead of two semesters) (Table 1): this allowed to avoid several issues related to academic calendars' asynchronicity. This also allowed easier and faster consensus among student on the problem definition and project scope.

- Travels of supervisors and students were limited accordingly with shorter duration of the cohort (Table 1).

- Problem domain was adopted from industrial partner: this allowed to increase students' motivation and engagement, and to limit their uncertainty about tasks.

- Interval between first and second physical meeting was shortened: this allowed more effective definition of the project scope and work breakdown.

- Number of physical meetings was limited to three (instead of four) consecutively to shorter cohort duration and smaller group.

The main responsibility on supervising students during physical meetings was laid on supervisors from the university, where the meeting was hosted. All the other supervisors were participating physically in limited time and otherwise virtually in regular teleconferences with students.

Table 1 Characteristics of cohorts

\begin{tabular}{|c|c|c|c|}
\hline Characteristic & Cohort 1 & Cohort 2 & Cohort 3 \\
\hline No. of students & 13 & 16 & 8 \\
\hline Duration & Apr 2016-Jan 2017 & Apr 2017-Jan 2018 & Mar 2018-Jun 2018 \\
\hline Orientation & \multicolumn{2}{|c|}{$\begin{array}{c}\text { New products (systems) in self-defined } \\
\text { sustainable domain }\end{array}$} & $\begin{array}{c}\text { Industry-based } \\
\text { sustainable problem } \\
\text { domain }\end{array}$ \\
\hline \multirow{4}{*}{$\begin{array}{l}\text { Physical } \\
\text { meetings }\end{array}$} & Warsaw (Apr 2016) & Milano (Apr 2017) & Berlin (Mar 2018) \\
\hline & Milano (Jun 2016) & Trondheim (May 2017) & Warsaw (Apr 2018) \\
\hline & Berlin (Oct 2016) & Berlin (Oct 2017) & Milano (Jun 2018) \\
\hline & Trondheim (Jan 2017) & Warsaw (Jan 2018) & \\
\hline \multirow[t]{2}{*}{ Results } & Pallet thermal cover & Limiting healthcare & \multirow{2}{*}{$\begin{array}{l}\text { Sustainable } \\
\text { opportunities for } \\
\text { automotive parts for } \\
\text { remanufacturing } \\
\text { company }\end{array}$} \\
\hline & $\begin{array}{l}2 \text { Modular quarter } \\
\text { pallet }\end{array}$ & $\begin{array}{ll} & \text { associated infections } \\
2 & \text { Small wind turbine }\end{array}$ & \\
\hline
\end{tabular}

\section{Project results}

\subsection{Cohort 1}

During an innovation workshop, the EET team chose 'excessive municipal solid waste and its inefficient disposal' as the overreaching field for the innovation. This field is related to the 12th sustainable development goal of the United Nation, which aims to ensure sustainable consumption and production patterns (Stock and Kohl, 2018). The team of 13 students decided to devise concepts for two complementary sustainable innovations, i.e.: 


\section{1 a thermal cover \\ 2 a quarter-pallet.}

The mandate of the Food and Agriculture Organization of the United Nations since 1945 has been to reduce food losses. Nonetheless, it is estimated that still half of the food grown is lost or wasted before and after it reaches the consumer (Lundqvist et al., 2008). Only $10 \%$ of worldwide perishable foods are refrigerated, yet refrigeration is the best known technology, with no associated risks, to prolong the shelf life of perishable food (FAO, 2019). Consequently, research efforts addressed aspects of food loss prevention in the cold supply chain. The role of food packaging in the supply chain has been already explored (Verghese et al., 2015) and new solutions for traceability have been developed (Aung and Chang, 2014). At the same time, some innovations go towards an integrated solution that aims at finding the best trade-off between food quality, energy consumption and global warming impact in cold chains (Gwanpua et al., 2015). The need for action in this field comes also from the expected compound annual growth rate of the refrigerated transports for perishables, which was assessed ca. $2.5 \%$ by 2020 against a volume of ca. 3,000 bln $\mathrm{kg}$ (Marketsandmarkets.com, 2015). Aligned with this growth, also the respective fuel consumption is significant. Today, a refrigerating unit of a $13.4 \mathrm{~m}$ semi-trailer consumes ca. 3-4 $\mathrm{dm}^{3} / \mathrm{h}$ of fuel (Tassou et al., 2009). The students' selection of the project for their EET coincided with the food lost prevention. The product that was chosen to be researched and developed is an integrated product that tackles both problems of food loss prevention and energy consumption. The solution consisted of a modular insulation cover for a pallet that aimed to reduce the thermal exchange between the external environment and goods on the pallet itself. The application of the pallet and the cover is for transportation of goods that require their temperature to be controlled during the transport, e.g., food or pharmaceuticals. Due to the insulation, the temperature of the transported products will change more slowly, thus reducing the need for using refrigerated vans for short distance transport (last mile delivery), and avoiding storage of the goods in refrigerated logistic bays when loading and unloading on different transportation vehicles. The insulation reduces the energy needed by refrigerated vehicles to guarantee that the temperature does not exceed given thresholds. The proposed design is made up of an insulated cover, with a metal structure to increase its rigidity and embedded temperature sensors. The metal structure aims at protecting the goods from damages, while the sensors aim at exchanging information on the temperature with external controlling devices to provide monitoring and support advanced control of a truck refrigeration system. The thermal pallet cover contribution to innovation with respect to current practices in the logistics of goods is two folded. The first one is the structure of the cover, which is designed to be used together with the standard euro pallet, covering the goods and, thanks to the structural reinforcements, allowing them to be stacked (Figure 3).

The second one relies on the use of embedded sensors enabling monitoring the temperature of the goods, and interacts with the external environment to support advanced management policies of refrigeration systems to reduce the energy consumption and, consequently, the associated cost of transportation. The students' selection of the project coincides with the food loss prevention. The product they decided to research and develop is an integrated product that tackles both problems of food loss: prevention and energy consumption (Gladysz et al., 2018). 
Figure 3 (a) Thermal cover - assembly (b) ICT component - general assembly (see online version for colours)

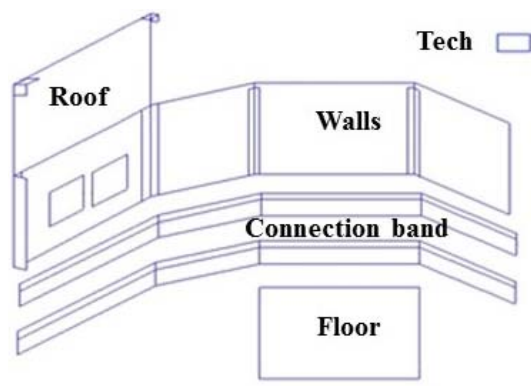

(a)

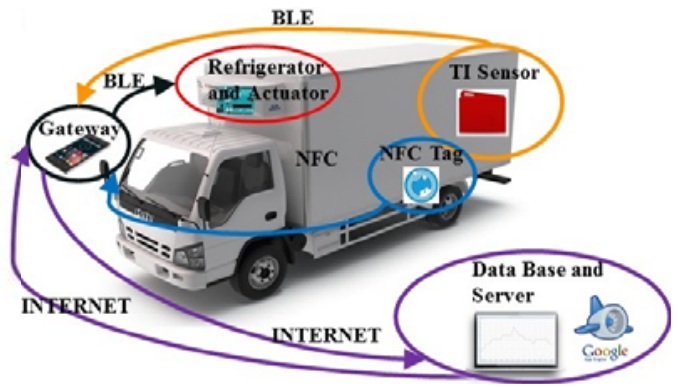

(b)

Source: Gladysz et al. (2018)

Figure 4 (a) Anchora pallet (b) Configuration of the value proposition (see online version for colours)

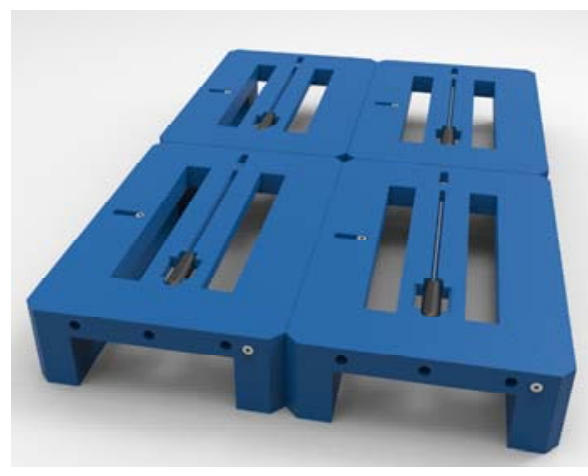

(a)

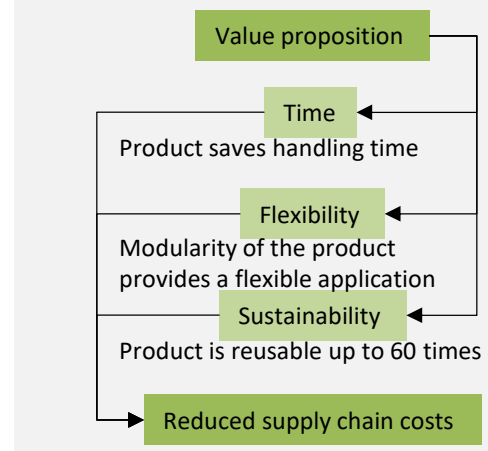

(b)

Source: Stock and Kohl (2018)

In 2014 , ca. $163 \mathrm{~kg}$ of packaging waste was generated in average per inhabitant in the EU. In order to improve the end-of-life phase for packaging waste, a directive of the European Parliament and Council increased the target rate for its reuse, recovery and recycling. This led to significant improvements in the recovery and recycling rates in the EU since 2009 (Eurostat, 2017). However, a further increase in these rates, a stronger focus on reuse, as well as a decrease in the amount of packaging waste can significantly improve the quality of life of the EU citizens and contribute to the sustainable consumption of resources. On the basis of current packaging approaches, new sustainable solutions should be developed. For identifying first customer needs in the field of sustainable solutions for packaging, the EET carried out an online survey and interviews with different companies. These activities revealed that the commonly used Euro pallets have only one size and are relatively cost expensive. Half-sized pallets are cheaper than regular sized pallets, more adaptable, and space saving. However, in terms of a customer demand for smaller sized pallets, these pallets are made for single-use only, leaving the end customer with the task of disposal. In conclusion, a solution idea for a novel sustainable pallet system was generated: the Anchora pallet (Figure 4). 
The pallet system is customisable and adaptable to the customers' needs and allows multiple use phases. The product and business model development followed the methodology of the diamond-model (Stock et al., 2017). In terms of the product development, only the mechanical domain was relevant for the development of the Anchora pallet system. Based on the customers' needs, first product requirements and functions had been derived. The requirements covered the set of specific properties for the product. The functions described the fundamental product functions and characteristics for fulfilling the product properties. For the product functions, specific solutions had been developed and realised in form of a design for a first virtual prototype. This prototype was subsequently manufactured in order to test and validate the functionality of the hooking mechanism between the quarter pallets. In a second iteration, the design of the first prototype was improved and led to the final design of the Anchora pallet. In terms of the business model, the customers, value proposition, value chain, and the revenue model had been developed. For this purpose, a vision for the business model was created by the students. The vision specifies the idea of the innovation as well as fundamental ideas and main requirements for the business model in general. Following this initial vision, different hypotheses for the customer segments, value proposition, value chain, and the revenue model were created. Hypotheses are first assumptions for shaping theses different domains of the business model. For the hypotheses, the students subsequently developed specific solutions which have already been proven in entrepreneurial practice. In order to test the different solutions, the first business model was presented to experts in the field of logistics and supply chain management during a pitch event. Based on the feedback during the pitch, a final archetype for the business model was developed. For the final business model, different use cases for potential first customers as well as an implementation plan was derived.

\subsection{Cohort 2}

The motivation for the first group of cohort 2 came from a report of the European Center for Disease Prevention and Control (2018) stating that approximately 4-million European patients every year get infected with healthcare-associated infections (HAIs), i.e., infections occurring during the process of care in a hospital or other healthcare institutions, causing at least 37,000 deaths per year. As an overall statement, HAIs are a serious problem causing a prolongation of hospital stay and increased cost and risk of mortality. Within the framework of the EET, the objective of the students was to develop methodologies and tools to reduce HAI in healthcare institutions and minimise the spread by means of increasing hygiene. The activities specifically focused on hand hygiene, based on the fact that just increasing the hand hygiene compliance from poor $(60 \%)$ to excellent $(80 \%)$ can result in a $48 \%$ reduction in the risk of acquiring infection (World Health Organization, 2014). For this reason, two main aspects have been taken into consideration: a tracking tool and methodology to check whether health operators (i.e., doctors, nurses, etc.) visit the hand washing areas after being in contact with the patients (Figure 5) as well as a vision-based monitoring system to check the effectiveness of the hand washing operation in compliance with the directives of the World Health Organization (2009) (Figure 6). The prototype implementation and experiments carried out, as well as market and feasibility analysis of the proposed approach resulted in a convincing set of tools and methodologies expected to provide a significant impact when applied to hospitals or healthcare institutions in general. The accompanying business 
model focuses on hospitals and other health care institutions such as nursing homes with future opportunities in schools and food processing locations. Revenue is generated initially through sale and implementation of the system. In the use phase, further revenue is generated through maintenance and consulting services, e.g. data analytics for risk assessment and disease control.

Figure 5 A scheme of the tracking approach (see online version for colours)

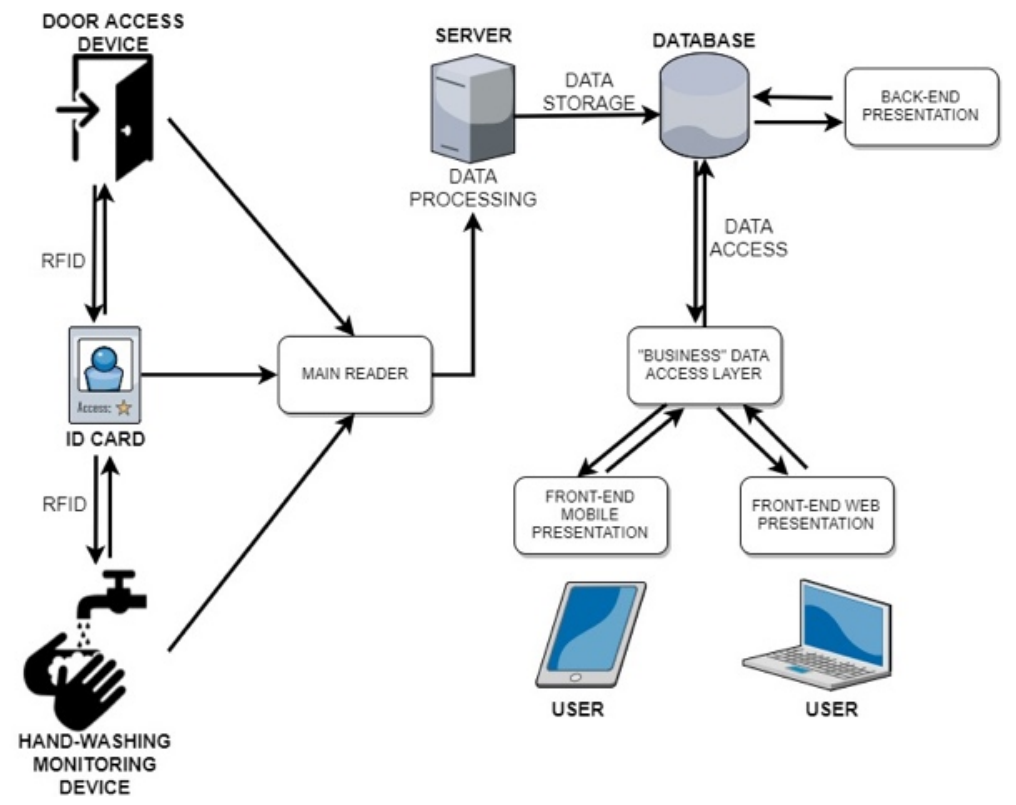

Figure 6 Prototype of the hand washing monitoring system (see online version for colours)

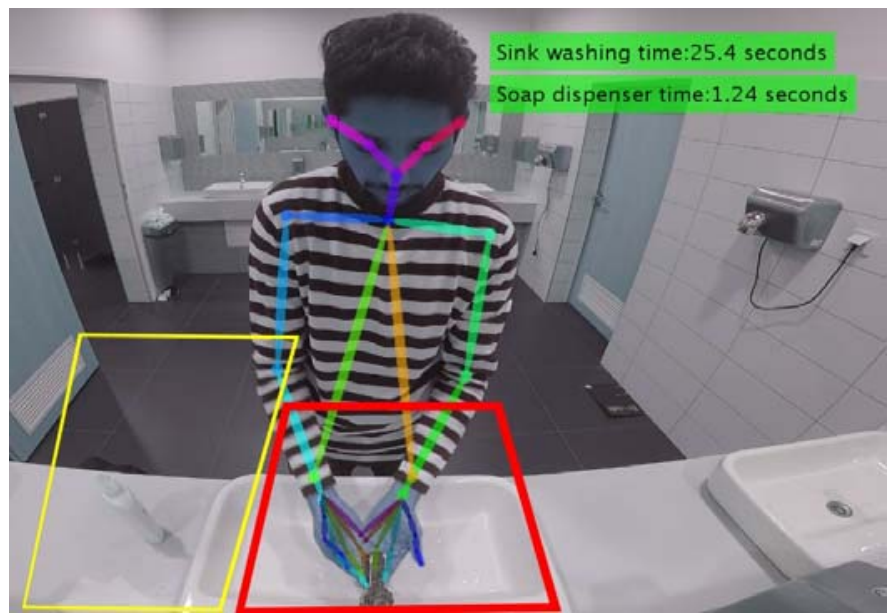

The motivation for the second group of cohort 2 derived from the fact that 1.2 billion people or $16 \%$ of the world population have no access to electrical energy (IEA, 2016). $95 \%$ of these people are living in sub-Saharan Africa and most of them in rural areas 
(URT, 2016). In order to tackle these conditions, the team pursued the sustainability goal of 'renewable energies' with the challenge of 'providing clean energy sources for the world'. As an initial solution idea for the value proposition, the EET came up a low-tech micro wind turbine for application in sub-Saharan Africa. Subsequently, the students started the development of the product and the business model. The product is based on a Savonius (1926) rotor (Akwa et al., 2012) with a bamboo mast and a battery for storing the wind energy as essential technical solutions (Figure 7). The rotor was prototypically build with minimal investment in materials and mostly available recycled parts, mainly an empty oil barrel and a car alternator, all components which are available for the designated user group.

Figure 7 Prototype of the micro wind turbine (see online version for colours)

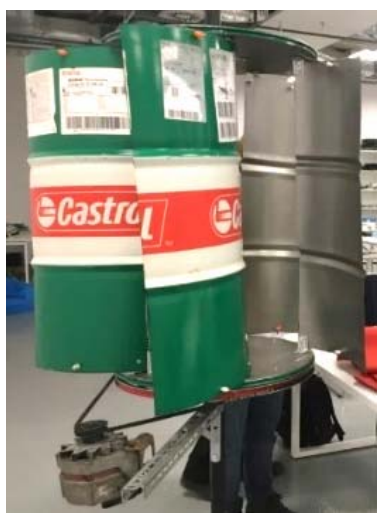

(a)

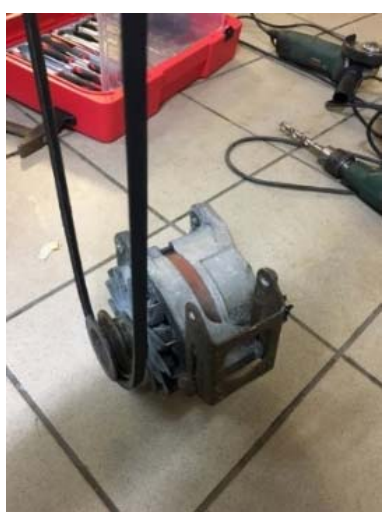

(b)

The Savonius rotor also serves as a barrel-shaped transport box for the wind turbine. This design has several advantages for the application in rural areas in sub-Saharan Africa. It has a simple mechanical design, and requires a low wind speed to operate. The first prototype delivers $5 \mathrm{~W}$ with a nominal wind speed of $4.5 \mathrm{~m} / \mathrm{s}$, which is sufficient to charge a phone or a LED light source. Ground level electronics enable easy maintenance and repair without in-depth knowledge. The students developed a business model which focuses on fostering local value creation in Tanzania. The product serves as an artefact for training local entrepreneurs to establish own businesses. The training is carried out by the start-up with the help of locally operating public organisations and NGOs. The use of locally available resources for the micro-wind turbine enables local added value. Customers are primarily farmers and fishermen in Tanzania, who make up $77-93 \%$ of the population and work self-employed to almost $80 \%$. The profit scheme of the start-up is based on the acquisition of donations and subsidies to finance the training activities. Possible sources of financing are private individuals, companies and public funding bodies. The cost structure is similar to NGOs such as 'Engineers without Borders'. The cost structure divides one euro into $70 \%$ for innovation development and $10 \%$ each for training, marketing and administration. 
Table 2 Decision scheme for the evaluation of alternative options through the AHP methodology

\begin{tabular}{|c|c|c|c|}
\hline$G O A L$ & Level 1 & Level 2 & Level 3 \\
\hline \multirow{19}{*}{$\begin{array}{l}\text { RECOVER } \\
\text { WASTE }\end{array}$} & Strategic & Entry barriers & \\
\hline & & Novelty and innovativeness & \\
\hline & & Market concentration & \\
\hline & Ecological & Material recovery & \\
\hline & & Energy & Energy consumption \\
\hline & & & Energy recovery \\
\hline & & Emission & $\mathrm{CO}_{2}$ \\
\hline & & & Heat \\
\hline & & & Noise \\
\hline & Technological & Installation & \\
\hline & & Local workers experience and skills & \\
\hline & & Integration with legacy systems & \\
\hline & Social & Local community & \\
\hline & & Employees satisfaction & \\
\hline & & Awareness & \\
\hline & Financial & Net present value & \\
\hline & & Discounted payback period & \\
\hline & & Initial outflow & \\
\hline & & Profitability index & \\
\hline
\end{tabular}

\subsection{Cohort 3}

For cohort 3, the student group worked on an industry-related problem in cooperation with a European remanufacturing company for automotive parts. The task was to identify suitable opportunities to deal with wastes in the production regarding unused raw materials (e.g., plastics, copper, aluminium and steel) as well defective components that could not be remanufactured. Based on company internal data and a process and waste analysis at a Polish production plant, the student team gathered possibilities to utilise the waste. From the large number of initial ideas out of a creativity workshop, a shortlist was compiled together internal experts. Subsequently, to select suitable solutions for implementation at the company, an analytic hierarchy process (AHP) (Saaty, 1990) was carried out. Possible solutions that were described and analysed in more detail were the repair of defective components with additive manufacturing (AM) technologies, recycling of metal and plastic parts to produce source material for AM and the conversion of plastic into oil for energetic use. In total, 19 economic, ecologic, social, technical and strategic criteria were defined (Table 2) and weighted in accordance with the company strategy by the project team and company experts. The production of powder for use in $\mathrm{AM}$ was identified as the most promising solution, in particular because of the high 
market price. Additionally, by using this powder in the internal remanufacturing processes, the economic viability of AM for remanufacturing can be improved. This results in new in-house applications for the repair of previously discarded components, and reduces the generation of waste. As a project result the company-specific AHP was described in the form of a guideline to be used continuously for decision-making under changing conditions, both for the already described solutions and as a generic template for new ones. Additionally, the identified promising solutions were described in detail, in order to be evaluated later with a cost-benefit analysis internally by the company.

\section{Course evaluation}

In order to ensure an effective course implementation, the activities of the first and second cohort were reviewed before, during and after its respective completion. The aim of the evaluation was on the one hand to guarantee the students a comprehensible and fair grading which reflects their performance and is necessary for the completion of their study programme. On the other hand, potentials for improvement with regard to the course structure, learning methods and content should be identified in order to be able to continuously develop the course. To this end, it was examined to what extent the learning curve of the students developed during the course, whether they have achieved their required learning goals and whether the general course framework has met these requirements.

In addition to the standard evaluation and grading of the students' project work by the supervisors, the teaching and learning effectiveness was evaluated through self-assessments by the students. For each cohort, three anonymous online surveys were conducted, a first survey directly at the start of the course, a second one in the middle and a final one after completing the course. Students rated their competencies with relation to the learning goals of the course on a scale from 0 (very poor) to 10 (excellent). Figures 8 and 9 show the results of the first and final survey for two cohorts.

Figure 8 Evaluation of the first cohort (see online version for colours)

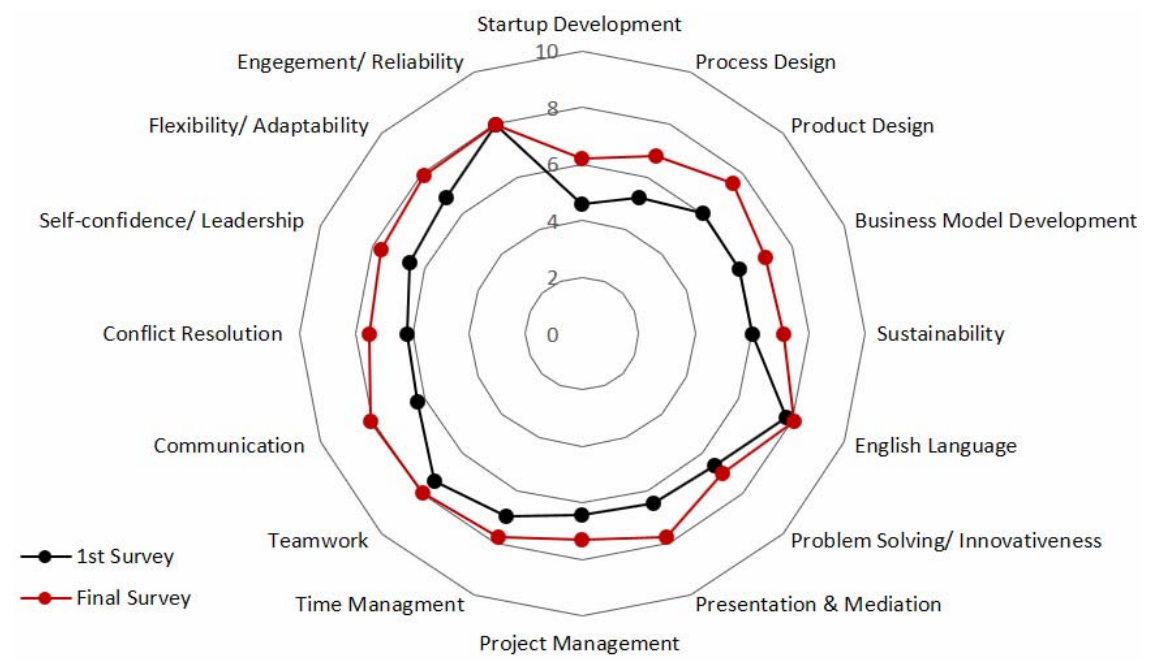


Figure 9 Evaluation of the second cohort (see online version for colours)

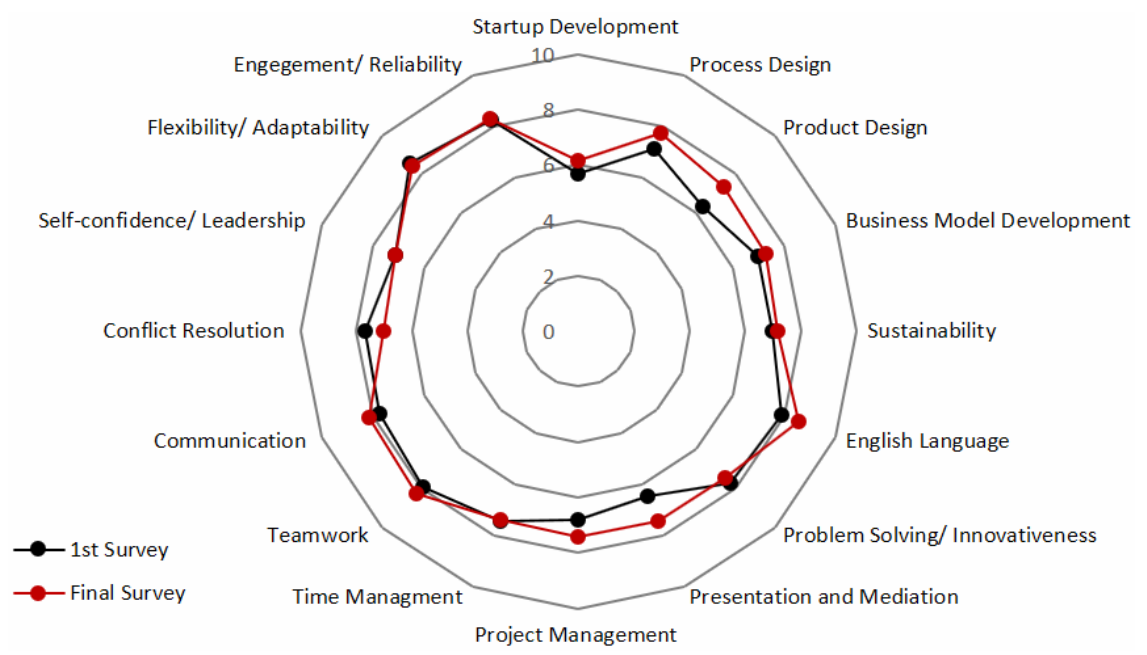

The self-assessment of the first cohort shows significant improvement of the relevant student competencies from 6.5 to 7.5 points on average. With regard to professional and methodical competencies, startup development, process design and product design have improved. Social competencies, in terms of presentation and mediation, communication as well as conflict resolution have improved too. Regarding self-competencies, the self-confidence/leadership as well as flexibility/adaptability increased. Because reliability, teamwork capability and English language skills were key criteria during the selection process of students for the course, it is reasonable to assume that the competencies in these areas were already very high at the beginning and could only be improved slightly.

For the second cohort, similar levels of learning goals could be achieved. With 7.3 points on average, the self-reported capabilities at the start of the course were already very high compared to the first cohort. However according to the supervisor evaluation, both cohorts started with similar capabilities. Because of the initial high placement, the relative improvement was lower. It should be noted that the self-assessment regarding the competency conflict resolution was even lower at the end of the course than at the beginning. This could be an indicator for a more realistic self-assessment as students were confronted with an internal conflict during the project. For both cohorts, the competencies communication as well as presentation and mediation were particularly promoted, since these were prominent features during the exercises and relevant for grading throughout the project. Regarding startup development, it is notable that for both cohorts a lower level was achieved compared to other competencies. As the startup development is one of the core topics of the course, there is still a need for improvement for future cohorts.

\section{Lessons learnt}

The aim of the described master module was manifold. The project conditions simulated real-world on-the-job environments for today's engineers and, as a consequence, a wide 
set of heterogeneous and complementary skills were required and stimulated. Students learned to use participatory democracy techniques to make decisions as a team and to manage conflicts. A brief introduction to the rudiments of systems engineering for problem solving helped them in their first meetings, but their fall-back process reduced to trial and error for much of the engineering decisions. Given the high level of initial uncertainty, the students achieved fairly significant personal and team growth. Finally, as a master module in engineering, students with different engineering backgrounds were put together with the aim to stimulate interdisciplinarity as the main solution approaches.

Grounding on the experience gained from the three cohorts and the comments provided by the students participating in the project, the following statements can be made:

a A clear and sound definition of the engineering area and theme is likely to help students to find their own way in addressing the problem. Although this could seem a relevant constraint, students will be provided a more structured environment, while retaining their freedom to learn and make mistakes.

b A stable set of teams for the whole duration of the activity supports a better level of interaction and cooperation, although this causes the impossibility of each student to get in touch with all the participants.

c Students needed to be specialised but, at the same time, have a clear global picture everyone should be concerned about business and sustainability matters, not just engineering, and to that end the business canvas should be introduced earlier in the process.

d Academic calendars can create transnational disconnects, a carefully coordination of these aspects is a primary ingredient for the success of the activity.

e Students need to be motivated to use a virtual collaboration platform and tools to increase transparency.

f Students should be advised that managing distance learning, work and communication is a complex process with a long learning curve.

g Supervisors should establish a continuous monitoring of the activities also in distance through group interim meetings (every 6-8 weeks) to facilitate cooperation and ensure coordination between the physical meetings.

$\mathrm{h}$ The availability of a concrete problem domain defined by a company is a winning factor to provide concreteness to the work and more commitment from the students.

These factors help to shorten the domain definition cycle, which leaves a more open schedule for designing and prototyping. As a result of implementing these recommendations, the second cohort has experienced a better introduction and made better progress throughout their first week of interaction. Additionally, the third cohort achieved comparable final results although the course duration was halved. The time gained can be used in particular for increased start-up development activities, such as external pitches and funding campaigns.

The lessons learned from three cohorts of the master course were utilised to develop a generic guideline for the planning an implementation of action-based and transnational courses in higher engineering education (Kohl et al., 2018). In the first stage the basic 
elements of the course are prepared. This includes the general learning objectives and content, teaching activities as well as target groups and participant's requirements. Additionally, relevant stakeholders have to be analysed and funding secured. Subsequently, the course can be developed in detail. The educational content is worked out, roles and expectations of learners and trainers are defined as well as a concept for quality assurance and rules for the communication between the stakeholders. In the third stage, the course is implemented. Project management and financial planning are required for an effectiveness conduction of the course. Periodic evaluations before, in-between and after completion of a cohort are used for continuous improvement.

\section{Conclusions}

Engineers today must be able to work in an international environment and cope with challenges of working in a team as well as cooperate and interact with colleagues remotely. For coping with the challenges related to the sustainable development goals as well as for fostering a sustainable transformation following the United Nation Agenda 2013, new approaches for teaching and learning in higher engineering education are required. Young engineers must be trained to anticipate these challenges and to contribute bottom-up to a global sustainable development by developing sustainable innovations. In addition, these young professionals must be capable of performing in more and more dynamic, transnational, and intercultural working environment in Europe. The aim of the EET courses was to provide engineering students an action-based learning experience where they become familiar with the aforementioned aspects. In the described activities, students were given the freedom of self-organising their work and learning from right decisions and mistakes. Cooperating with international colleagues both physically and virtually has been the only viable way to be successful. During the activities, they were taught in an environment simulating real-life on-the-job conditions and followed the process of innovation and new product development from the very beginning.

The experience of the all cohorts provides a strong evidence of the interest and benefits coming from this approach to learning engineering skills. Moreover, the aim at achieving a result that could become a business opportunity has been strongly appreciated by the students. Partner universities are focused on further cooperation based on experiences of EET. Transnational and project-oriented concepts seem to provide the future key competencies for young professionals. A framework of the transnational and project-oriented master course 'European Engineering Team' for training the key competencies has been outlined. The master course aims at developing sustainable innovations by applying a problem solving procedure based on Kolb's learning styles and by following a diamond-model for providing a structure of the start-up development. The results of three cohorts of the EET have been described regarding the technical solutions as well as the accompanying business models. The EET cohorts managed to adopt Vernon (2000) and Jack (2011) guidelines and overcome barriers listed by Sharma et al. (2017) in terms of being student-centred, project-oriented, including elements of economics and management, encourage students to pursue international travel and projects, incorporating topics that support global manufacturing and, in particular, encouraging teaching methods that engage students. The combined experiences of all 
cohorts were used to create guidelines for further development of the course as well as future implementations for similar formats.

\section{Acknowledgements}

This research was supported by the ERASMUS+ Strategic Partnerships Project 'New Culture in Higher Education: Project-Oriented Learning beyond Borders' funded by the European Union, project number 2015-1-DE01-KA203-002207.

\section{References}

Akwa, J.V., Vielmo, H.A. and Petry, A.P. (2012) 'A review on the performance of Savonius wind turbines', Renewable and Sustainable Energy Reviews, Vol. 16, No. 5, pp.3054-3064.

Aung, M.M. and Chang, Y.S. (2014) 'Traceability in a food supply chain: safety and quality perspectives', Food Control, Vol. 39, No. 5, pp.172-184.

BASE (2017) BASE Bottom-Up Climate Adaption Strategies towards a Sustainable Europe, 27 April, Von BASE Transnational Training Course, base-adaptation.eu/base-transnationaltraining-course.

Dewey, J. (2007) Experience and Education, Simon and Schuster, New York (NY).

European Center for Disease Prevention and Control (2018) Healthcare-Associated Infections, 11 May [online] http://ecdc.europa.eu/en/healthcare-associated-infections (accessed 11 May 2018).

Eurostat (2017) Packaging Waste Statistics, 29 August [online] http://ec.europa.eu/eurostat/ statistics-explained/index.php/Packaging_waste_statistics (accessed 26 November 2019).

FAO (2019) WCCS, 27 January [online] http://www.fao.org/save-food/news-and-multimedia/ events/detail-events/en/c/447383/ (accessed 27 January 2019).

Gladysz, B., Urgo, M., Gaspari, L., Pozzan, G., Stock, T., Haskins, C., ..., Kohl, H. (2018) 'Sustainable innovation in a multi-university master course', Procedia Manufacturing, Vol. 21, No. 1, pp.18-25.

Glassey, J. and Haile, S. (2012) 'Sustainability in chemical engineering curriculum', International Journal of Sustainability in Higher Education, Vol. 13, No. 4, pp.354-364.

Gwanpua, S.G., Verboven, P., Leducq, D., Brown, T., Verlinden, B. E., Bekele, E., ..., Taoukis, P. (2015) 'The FRISBEE tool, a software for optimising the trade-off between food quality, energy use, and global warming impact of cold chains', Journal of Food Engineering, Vol. 148, pp.2-12.

IEA (2016) World Outlook 2016: Executive Summary, OECD/IEA, Paris.

Jack, H. (Ed.) (2011) Curricula 2015. A Four Year Strategic Plan Manufacturing Education, Society of Manufacturing Engineers (SME).

Kohl, H., Stock, T., Sieckmann, F., Tollio, T., Urgo, M., Strandhagen, J.O., Haskins, C., Jarzebowska, E. and Gladysz, B. (2018) Guideline for the Planning and Implementing an Action-Based and Transnational Course in Higher Engineering Education [online] http://www.engineering-team.net/docs/guideline/ (accessed 26 November 2019).

Kolb, A.Y. and Kolb, D.A. (2005) 'Learning styles and learning spaces: enhancing experiential learning in higher education', Academy of Management Learning \& Education, Vol. 4, No. 2, pp.193-212.

Kolb, D. (1984) Experiential Learning: Experience as the Source of Learning and Development, Prentice Hall, Englewood Cliffs (NJ). 
Kurtz, B.L., Fenwick Jr., J.B., Ellsworth, C.C., Yuan, X., Steele, A. and Jia, X. (2007) 'Inter-university software engineering using web services', Proceedings of 38th SIGCSE, pp.464-468, ACM.

Lane, T. (1994) 'Educating European construction managers of the future: the development of a transnational taught master's course', European Journal of Engineering Education, Vol. 19, No. 4, pp.443-448.

Lundqvist, J., de Fraiture, C. and Molden, D. (2008) Saving Water: From Field to Fork: Curbing Losses and Wastage in the Food Chain, Stockholm International Water Institute, Stockholm.

May, D., Wold, K.A. and Moore, S.L. (2014) 'Developing cultural competencies through transnational learning experiences in active online learning environments', International Journal of Engineering Pedagogy (iJEP), Vol. 4, No. 5, pp.12-19.

Marketsandmarkets.com (2015) Refrigerated Transport Market [online] http://marketsandmarkets. com/Market-Reports/refrigerated-transport-market-779494.html (accessed 30 March 2018).

Paasivaara, M., Lassenius, C., Damian, D., Räty, P. and Schröter, A. (2013) 'Teaching students global software engineering skills using distributed scrum', Proceedings of the 35th ICSE, pp.1128-1137, IEEE Press.

Paci, A.M., Lalle, C. and Chiacchio, M.S. (2013) 'Education for innovation: trends, collaborations and views', Journal of Intelligent Manufacturing, Vol. 24, No. 3, pp.487-493.

Perdan, S., Azapagic, A. and Clift, R. (2000) 'Teaching sustainable development to engineering students', International Journal of Sustainability in Higher Education, Vol. 1, No. 3, pp.267-279.

Petrea, E. and Velescu, E. (2014) 'An example of science students' interaction in a foreign language for the implementation of inter-university research projects', Procedia - Social and Behavioral Sciences, Vol. 141, No. 1, pp.707-711.

Piaget, J. (1964) 'Development and learning', in Ripple, R. and Rockcastle, V. (Eds.): Piaget Rediscovered: A Report on the Conference of Cognitive Studies and Curriculum Development, pp.7-20, Cornell University, Ithaca (NY).

POLE (2018) FH Nordwestschweiz, Pole - On Track (A-WELLE), 20 April [online] http://web.fhnw.ch/technik/projekte/i/ip512/pole/index.html (accessed 26 November 2019).

Reich, R. (1990) Redefining Good Education: Preparing Students for Tomorrow, in Bacharach, S. (Ed.): Education Reform: Making Sense of it All, Allyn and Bacon, Boston (MA).

Saaty, T.L. (1990) 'How to make a decision: the analytic hierarchy process', European Journal of Operational Research, Vol. 48, No. 1, pp.9-26.

Savonius, S.J. (1926) The Wing-Rotor in Theory and Practice, Savonius\&Co., Helsgingfors.

Schein, E.H. (1996) 'Kurt Lewin's change theory in the field and in the classroom: notes toward a model of managed learning', Systems Practice, Vol. 9, No. 1, pp.27-47.

Sengupta, D., Huang, Y., Davidson, C.I., Edgar, T.F., Eden, M.R. and El-Halwagi, M.M. (2017) 'Using module-based learning methods to introduce sustainable manufacturing in engineering curriculum', International Journal of Sustainability in Higher Education, Vol. 18, No. 3, pp.307-328.

Sharma, B., Steward, B., Ong, S.K. and Miguez, F.E. (2017) 'Evaluation of teaching approach and student learning in a multidisciplinary sustainable engineering course', Journal of Cleaner Production, Vol. 142, No. 4, pp.4032-4040.

Shields, D., Verga, F. and Blengini, G.A. (2014) 'Incorporating sustainability in engineering education: adapting current practices to mining and petroleum engineering education', International Journal of Sustainability in Higher Education, Vol. 15, No. 4, pp.390-403.

Stansinoupolos, P., Smith, M.H., Hargroves, K. and Desha, C. (2013) Whole System Design: An Integrated Approach to Sustainable Engineering, Routledge, London.

Stock, T. and Kohl, H. (2018) 'Perspectives for international engineering education: sustainable-oriented and transnational teaching and learning', Procedia Manufacturing, Vol. 21, No. 1, pp.10-17. 
Stock, T., Obenaus, M., Slaymaker, A. and Seliger, G. (2017) 'A model for the development of sustainable innovations for the early phase of the innovation process', Procedia Manufacturing, Vol. 8, No. 1, pp.215-222.

Tassou, S.A., De-Lille, G. and Ge, Y.T. (2009) 'Food transport refrigeration - approaches to reduce energy consumption and environmental impacts of road transport', Applied Thermal Engineering, Vol. 29, Nos. 8-9, pp.1467-1477.

URT (2016) The United Republic of Tanzania, Energy Access Situation Report 2016: Tanzania Mainland [online] http://nbs.go.tz/nbs/takwimu/rea/Energy_Access_Situation_Report_ 2016.pdf (accessed 10 May 2018).

Verghese, K., Lewis, H., Lockrey, S. and Williams, H. (2015) 'Packaging's role in minimizing food loss and waste across the supply chain', Packaging Technology Science, Vol. 28, No. 7, pp.603-620.

Vernon, J. (2000) 'Engineering education: ending the centre or back to the future', European Journal of Engineering Education, Vol. 25, No. 3, pp.215-225.

World Health Organization (2009) Guidelines on Hand Hygiene in Health Care, WHO, Geneva.

World Health Organization (2014) Evidence of Hand Hygiene to Reduce Transmission and Infections by Multi-Drug Resistant Organisms in Health-Care Settings, WHO, Geneva.

Ziemian, C.W. and Sharma, M.M. (2008) 'Adapting learning factory concepts towards integrated manufacturing education', International Journal of Engineering Education, Vol. 24, No. 1, pp.199-210. 